\title{
Review on Power Quality Enhancement and its effects on Micro Grid
}

\author{
Ankeeta \\ M.Tech Scholar \\ Power System \\ Technocrats Institute of Technology Group of \\ Institutes \\ Bhopal, M.P, India \\ amazingankeeta1995@gmail.com
}

\author{
Vasant Acharya \\ Assit. Professor \\ Department of Electrical and Electronics Engineering \\ Technocrats Institute of Technology Group of \\ Institutes \\ Bhopal, M.P, India \\ vasantacharyatitc@gmail.com
}

\begin{abstract}
Power generation through the renewable energy sources has become more viable and economical than the fossil fuel based power plants. By integrating small scale distributed energy resources, microgrids are being introduced as an alternative approach in generating electrical power at distribution voltage level. The power electronic interface provides the necessary flexibility, security and reliability of operation between microsources and the distribution system. The presence of nonlinear and the unbalanced loads in the distribution system causes power quality issues in the Microgrid system. This paper explores and reviews different control strategies developed in the literature for the power quality enhancement in microgrids.
\end{abstract}

Keywords: Microgrids, Solar System, Photovoltaic, Controller.

\section{INTRODUCTION}

Conventional power systems are facing problems like depletion of fossil fuels, poor energy efficiency and environmental pollution etc. Also the ever increasing demand for reliable and quality power delivery put lot of pressure on conventional power system. All these have paved the way for the generation of power locally at distribution voltage level with the help of non-conventional / Renewable energy resources like wind, solar photovoltaic cells, hydro, natural gas, biogas, fuel cells etc., [1]. The power system reliability can also be improved by way of integration of large number of small distributed energy resources (DER) [2]. DERs are usually of smaller capacity having low energy density, as they are dependent on geographical nature of a region.

The transmission and distribution losses are minimized as the power generation at distribution voltage level is very closer to the load centers. A DER can be directly connected to the distribution network or can be interconnected to form microgrid (MG). DERs can be
Used to perceive the benefits like increased energy efficiency, reduced carbon emission and improved power quality and reliability (PQR) [3]. In [4], integration of DERs, operation of microgrid, its control aspects, power quality issues in microgrid system is elaborated. In addition to these advantages, the performance and efficiency of Distributed generation (DG) has been significantly improved due to the advancements in the power electronics technology. Deployment of inverter interfaced DG in power systems mitigates the peak load and improves the power quality [5],[6].

A microgrid (MG) is a group of loads, DG units and energy storage systems (ESS) that operate in coordination to the power system at the distribution voltage level. The point at which the microgrid is connected to the main grid is called point of common coupling (PCC). Generally, microgrids are operated in grid connected mode; but it is usually designed in such a way that they have sufficient amount of power to feed in atleast a part of the load even after the disconnection from the utility grid.

The control and operational strategy needs to be taken care for the operation of microgrid which remains in isolated (islanded) mode of operation. Based on the type of distributed energy resource (DER) units, their level of dissemination, characteristics of load connected and power quality constraint, the control and operation of microgrid is different from that of traditional power generation systems. 


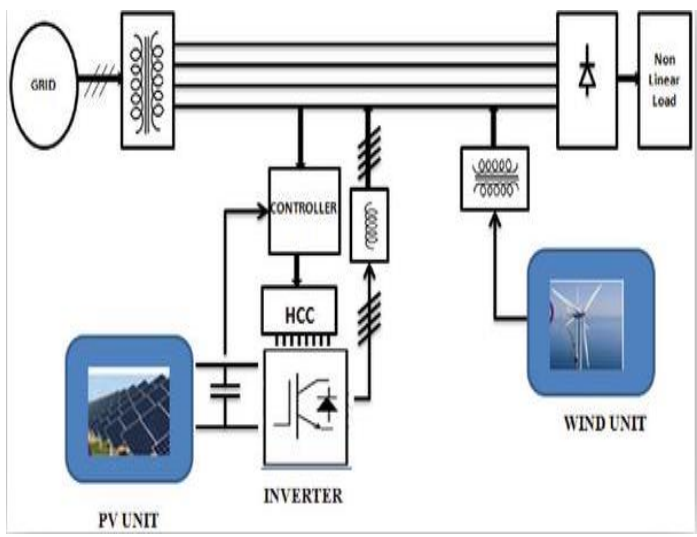

Figure 1 Block diagram of renewable source integrated grid system.

In grid connected MG system, the system dynamics are taken care by the utility itself whereas in islanded mode, the dynamics are dictated by the micro sources themselves. MG acts as a single controlled entity i.e., as an aggregated load within the power system and it supplies uninterruptible power to meet the local electrical/ heat requirements, increases reliability, minimizes the losses and offers good voltage support. In utility connected mode of operation, the micro sources are being controlled to supply the stipulated power in to the system and the microgrid should be designed in such a way that smooth transition takes place from grid connected to isolated mode or vice versa depending upon the grid conditions.

\section{LITERATURE REVIEW}

V Lavanya et al. [1]in this paper of the power generation through the renewable energy sources has become more viable and economical than the fossil fuel based power plants. By integrating small scale distributed energy resources, microgrids are being introduced as an alternative approach in generating electrical power at distribution voltage level. The power electronic interface provides the necessary flexibility, security and reliability of operation between micro-sources and the distribution system. The presence of non-linear and the unbalanced loads in the distribution system causes power quality issues in the Microgrid system. This paper explores and reviews different control strategies developed in the literature for the power quality enhancement in microgrids. Also comparisons of different control methods are presented with suggestions for future research.

By Gaspard d'Hoop et al. [2]This algorithm is simulated for different scenarios on a conceptual test-case microgrid with residential, industrial, and commercial loads. The results show that the demand-side management mechanism inside the algorithm can adapt efficiently the consumption behavior of certain loads, so that the voltage drop, the voltage total harmonic distortion, and the voltage unbalance factor meet the required standards at every node of the microgrid during the day. It is also highlighted that the microgrid can gradually reduce the purchase of power from the utility grid to which it is connected if the electricity price on the spot market increases.

Bhupendra Singh Niranjan et al. [3] in this study in this improvement of the quality of the power is seen e.g. as sag, swell, over voltages, under voltage, and harmonics Conventional equipment for enhancement of power quality is becoming inadequate. Unified power quality conditioner (UPQC) is one modern device which deals with voltage and current imperfections simultaneously. The unified power quality conditioner (UPQC), which consists of the parallel active power filter (PAPF) and the series active power filter (SAPF). The UPQC is a power conditioning device able to compensate all kinds of power quality faults. UPQC is also used to filter both current and voltage harmonics and to compensate the voltage sag. UPQC has the capability of improving power quality at the point of installation on power distribution systems or industrial power systems. This work deals with a way to improve the voltage compensation performance of the series APF. This improvement is achieved by improving the conventional hysteresis control system.

Phani Kumar et al. [4]This paper presents a review on power quality problems associated with the integration of renewable energy systems in to grid and it shows how power electronic devices and Flexible AC Transmission Systems play a role to mitigate the power quality problems. Photo Voltaic (PV) and Wind energy systems integration issues and associated power quality problems are discussed. Classification of various Power Quality Issues used by different researchers has been done and put for reference. Application of various techniques as applied to mitigate the different Power Quality problems is also presented for consideration.

\section{POWER QUALITY IN MICROGRIDS}

Power quality is defined as maintaining a pure sinusoidal voltage waveform with the defined magnitude and frequency within the prescribed limit without having any deviations in the shape and the magnitude [1]. Power quality disturbances take place in a system when there is any deviation in magnitude and frequency of the power waveform beyond the specified range; hence creates problems to a customer. The different types of power quality disturbances are:

(1) Voltage unbalance, 
(2) Transients,

(3) Voltage sags and swells

(4) Over-voltages and under-voltages,

(5) Outage,

(6) Harmonic distortion,

(7) Voltage notching,

(8) Flicker and

(9) Electrical noise. Due to the presence and widespread use of several sensitive electrical and electronic gadgets in industrial and commercial sectors, Power Quality and Reliability issues have gained importance in the recent years. Distributed generation (DG) and integration of resources (DERs) in the form of microgrids helps to improve the power quality and hence the reliability of the power delivered in meeting the needs of the customers. The capability of microgrids operating in two different modes helps to supply the high priority / critical loads during the periods of power failure from the utility grid. The transition from gridconnected to stand-alone modes can be done by the seamless operation of Static.

Power quality is a major concern in small scale islanded systems because of the presence of non-linear and unbalanced loads, which forms a larger proportion of the total load. In islanding mode, the disturbances like voltage distortion and unbalance are most likely case as the line impedance is very high and the load distribution is of uneven when compared with the grid connected mode. In order to filter out the harmonics and to suppress the unbalance, the power electronic interface converter (inverter) can be controlled effectively. In grid connected mode, the disturbances like unbalanced utility voltages and voltage sag are the most frequent problems.

\section{CONTROL METHODS FOR VOLTAGE AND POWER FLOW CONTROL IN MICROGRID}

The structure of inverter based microgrid is shown in Fig. 2. The controller of an interfacing inverter includes power control loop, voltage control loop and current control loop. The external power control loop includes droop characteristics for real and reactive power in order to maintain the magnitude and frequency of the inverter output voltage. The voltage and current controllers are used to eliminate the high frequency disturbances and hence damping out the oscillations with the help of filter.

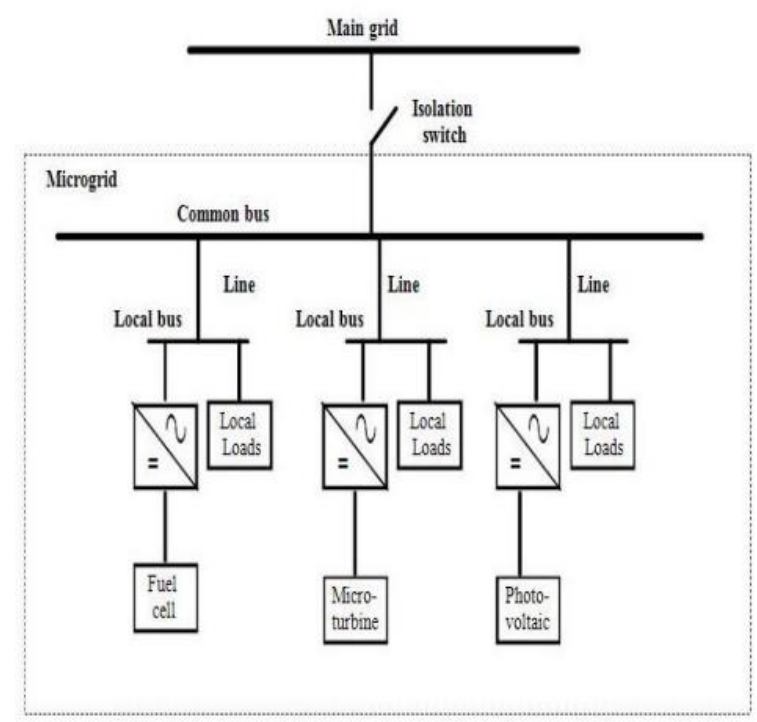

Figure 2. Structure of Inverter based Microgrid

\section{DROOP CONTROL METHOD}

Droop control is an efficient method which is mainly used to improve the real and reactive power control. Droop controllers are applicable for both modes of operation of a microgrid. The active power-frequency (P- $\omega)$ droop controller and reactive power-voltage (Q-V) droop controller are used in microgrid systems to achieve power sharing. The block diagram of droop controllers used for real and reactive power sharing are shown in Fig. 3 and Fig.4.

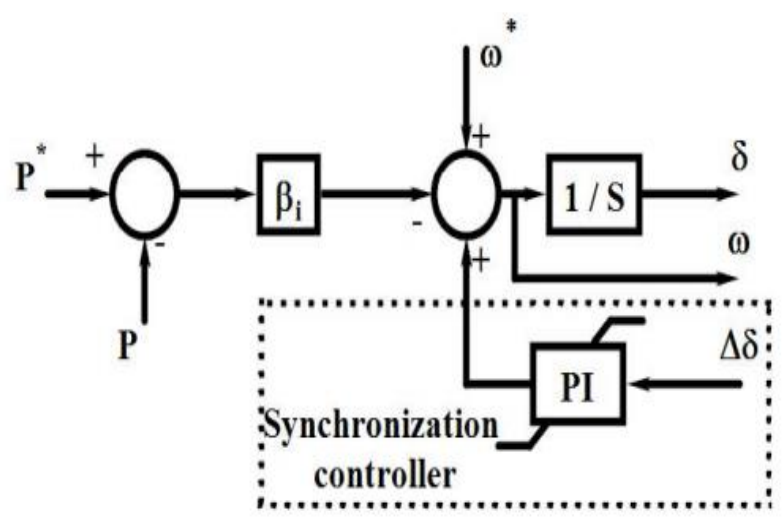

Figure 3. Real power compensation 


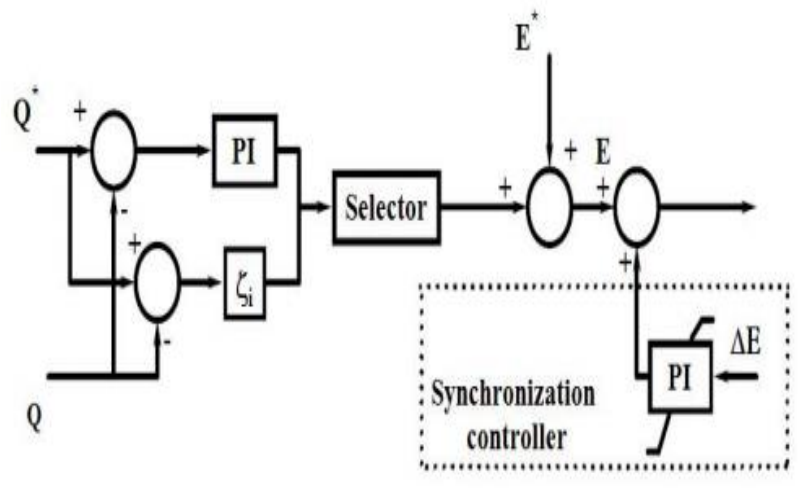

Figure 4. Reactive power compensation

\section{CONCLUSION}

This paper has explored the developments in microgrid and its control for the improvement of power quality. The different control strategies implemented in literature for the enhancement of power quality in both isolated and grid connected microgrid systems under unbalanced and nonlinear load conditions have been discussed. In the field of renewable energy, as the research and development all over the world is mainly focusing in the real time implementation of smart grid, the study of microgrid, its control strategies and the challenges in integrating with the utility aiming to generate and feed quality and reliable power to the grid /customers is very well needed. The major concern in the near future will be the integration of microgrid in to the existing power system, due to the variable nature of renewable energy sources and its rapid growth. Hence it is necessary to take measures to improve the control aspects so as to integrate the microgrid with the main grid effectively with improved power quality.

\section{REFERENCE}

[1] V Lavanya, N Senthil Kumar "A Review: Control Strategies for Power Quality Improvement in Microgrid" INTERNATIONAL JOURNAL of RENEWABLE ENERGY RESEARCH Vol.8, No.1, March, 2018

[2] By Gaspard d'Hoop, Olivier Deblecker "Power Quality Improvement of a Microgrid with a Demand-Side-Based Energy Management System" DOI: 10.5772/intechopen.83604 February 1st 2019.

[3] Bhupendra Singh Niranjan,Dashrath Kumar "Power Quality Improvement by Using UPQC in Wind Energy Conversion System" Vol. 8, Issue 3, March 2019

[4] Phani Kumar "A Review on Power Quality in Grid Connected Renewable Energy System” December 2013

[5] Omid Palizban, and Kimmo Kauhaniemi, "Hierarchical control structure in microgrids with distributed generation: Island and grid-connected mode",
Renewable and Sustainable Energy Reviews, Vol. 44, pp. 797-813, 2015.

[6] T.L. Vandoorn, J.D.M. De Kooning, B. Meersman, and L. Vandevelde, "Review of primary control strategies for islanded microgrids with power-electronic interfaces", Renewable and Sustainable Energy Reviews, Vol. 19, pp. 613-628, 2013 